\title{
Fluvial sedimentary deposits as carbon sinks: organic carbon pools and stabilization mechanisms across a Mediterranean catchment
}

\author{
María Martínez-Mena $^{1}$, María Almagro ${ }^{2}$, Noelia García-Franco ${ }^{3}$, Joris de Vente ${ }^{1}$, Eloisa García ${ }^{1}$, and \\ Carolina Boix-Fayos ${ }^{1}$ \\ ${ }^{1}$ Soil Erosion and Conservation Research Group, CEBAS-CSIC, Spanish Research Council, \\ Campus de Espinardo 30100, P.O. Box 164, Murcia, Spain \\ ${ }^{2}$ BC3-Basque Centre for Climate Change, Sede Building 1, 1st floor, Scientific Campus of the, \\ University of the Basque Country, 48940, Leioa, Spain \\ ${ }^{3}$ Chair of Soil Science, TUM School of Life Sciences Weihenstephan, Technical University of Munich, Emil-Ramann-Strasse \\ 2/I, 85354 Freising, Germany
}

Correspondence: María Martínez-Mena (mmena@cebas.csic.es)

Received: 17 September 2018 - Discussion started: 5 October 2018

Revised: 20 February 2019 - Accepted: 4 March 2019 - Published: 15 March 2019

\begin{abstract}
The role of fluvial sedimentary areas as organic carbon sinks remains largely unquantified. Little is known about mechanisms of organic carbon (OC) stabilization in alluvial sediments in semiarid and subhumid catchments where those mechanisms are quite complex because sediments are often redistributed and exposed to a range of environmental conditions in intermittent and perennial fluvial courses within the same catchment. The main goal of this study was to evaluate the contribution of transport and depositional areas as sources or sinks of $\mathrm{CO}_{2}$ at the catchment scale. We used physical and chemical organic matter fractionation techniques and basal respiration rates in samples representative of the three phases of the erosion process within the catchment: (i) detachment, representing the main sediment sources from forests and agricultural upland soils, as well as fluvial lateral banks; (ii) transport, representing suspended load and bedload in the main channel; and (iii) depositional areas along the channel, downstream in alluvial wedges, and in the reservoir at the outlet of the catchment, representative of medium- and long-term residence deposits, respectively. Our results show that most of the sediments transported and deposited downstream come from agricultural upland soils and fluvial lateral bank sources, where the physicochemical protection of $\mathrm{OC}$ is much lower than that of the forest soils, which are less sensitive to erosion. The protection of $\mathrm{OC}$ in forest soils and alluvial wedges (medium-term depositional areas) was mainly driven by physical protection (OC
\end{abstract}

within aggregates), while chemical protection of OC (OC adhesion to soil mineral particles) was observed in the fluvial lateral banks. However, in the remaining sediment sources, in sediments during transport, and after deposition in the reservoir (long-term deposit), both mechanisms are equally relevant. Mineralization of the most labile OC (the intraaggregate particulate organic matter $\left(M_{\text {pom }}\right)$ was predominant during transport. Aggregate formation and OC accumulation, mainly associated with macroaggregates and occluded microaggregates within macroaggregates, were predominant in the upper layer of depositional areas. However, OC was highly protected and stabilized at the deeper layers, mainly in the long-term deposits (reservoir), being even more protected than the OC from the most eroding sources (agricultural soils and fluvial lateral banks). Altogether our results show that both medium- and long-term depositional areas can play an important role in erosive areas within catchments, compensating for $\mathrm{OC}$ losses from the eroded sources and functioning as $\mathrm{C}$ sinks.

\section{Introduction}

Soil erosion, a complex process that causes the transport and deposition of sediments with accompanying soil organic carbon (SOC) (Gregorich et al., 1998; Wang et al., 2014), affects the dynamics of the terrestrial carbon $(\mathrm{C})$ cycle and 
has important implications for the rate of $\mathrm{C}$ inputs into the soil (i.e., plant net primary productivity), as well as for the accumulation and stability of organic matter in soil (Berhe and Kleber, 2013). According to some authors (Van Oost et al., 2007), lateral C fluxes are key to determining the fate of soil organic carbon (SOC) at the landscape scale. However, current estimations of those fluxes (based on soil erosion and the associated SOC content) show high variation among studies (Quinton et al., 2010; Doetterl et al., 2012). The fate of the redistributed organic carbon (OC) depends on multiple factors: (i) the nature of the soil organic matter being detached from different "sources" within a catchment (Nadeu et al., 2011, 2012; Kirkels et al., 2014); (ii) its turnover rates during transport; (iii) the type of erosion processes (selective or nonselective); (iv) the connectivity and distance of travel between eroding sources and the streambed (Boix-Fayós et al., 2015; Wang et al., 2010); and (v) the microenvironmental conditions under which the $\mathrm{OC}$ is stored in sedimentary settings (Van Hemelryck et al., 2011; Berhe and Kleber, 2013). All these factors, which affect the protection of OC against decomposition through physical and chemical mechanisms, remain considerably uncertain. Despite the fact that a combination of different techniques (isotopic, spectroscopic, and traditional wet chemistry) has been used (Wang et al., 2014; Kirkels et al., 2014; Liu et al., 2018) to determine if the eroded OC is lost after erosional redistribution, a full understanding of the dynamics and interactions between OC sources and sinks, in relation to soil erosion and redistribution, is still absent (Doetterl et al., 2016; Hoffman et al., 2013).

Determination of how the different OC pools are transported by erosion from different sources, as well as the effect of new soil structure formation by aggregation and OC stabilization after deposition, can partially contribute to answering this question (Doetterl et al., 2016). In fact, it is already known that soil aggregates physically protect $\mathrm{OC}$ from rapid decomposition by microorganisms (Razafimbelo et al., 2008; Six et al., 2000), and aggregate formation appears to be closely linked to soil C storage and stability (Barreto et al., 2009; Golchin et al., 1995; Salomé et al., 2010). Related to this, Wang et al. (2014) found that soil erosion and transport result in disaggregation and, consequently, SOC mineralization (Lal, 2005; Boix Fayos et al., 2015), while depositional and burial processes promote the formation of macroaggregates that contribute to the physical stabilization or protection of soil organic matter from decomposition, and enhance sorptive interactions of soil minerals with organic matter protecting OC from microbial decomposition (Berhe et al., 2013) The protection provided by macroaggregates as an important mechanism for SOC stability in soils affected by soil erosion processes has also been reported (Berhe et al., 2018; Nie et al., 2018). However, to the best of our knowledge, this is the first study to include the assessment of microaggregates contained within macroaggregates and their associated OC, widely acknowledged as an indicator of the physical protec- tion of SOC (Six et al., 2004; Denef et al., 2007; Six and Paustian, 2014), during the different phases of soil erosion at the catchment scale.

Several authors have suggested that alluvial settings are important nonquantified OC sinks (Wisser et al., 2013; Hoffmann et al., 2013; Ran et al., 2014) with mechanisms of OC stabilization that can be quite complex in semiarid and subhumid areas. In these areas sediments are often redistributed and exposed to a wide range of environmental conditions (e.g., rewetting-drying cycles, high temperatures, and solar radiation) and sub-catchments with ephemeral, intermittent, and perennial fluvial courses, sometimes within the same catchment (Boix-Fayos et al., 2015). Ephemeral and intermittent fluvial courses represent more than $50 \%$ of the global river network, being the dominant type of water course in dry climates (Datry et al., 2014). In addition, it is expected that this percentage will increase worldwide in response to climate change and increased water extraction for human use (Schewe et al., 2014) because intermittent and ephemeral rivers will suffer more severe, sustained, and more frequent droughts (De Girolamo et al., 2017; Vadher et al., 2018). Thus, understanding the OC stabilization mechanisms within these fluvial systems might have important implications for the stability of soil OC stocks as affected by soil erosion and in response to climate change. Moreover, the quantification of mineralization rates and the assessment of the stabilization mechanisms of OC induced by soil erosion, together with the identification of source materials contributing to the sediment OC dynamics within a catchment, are key to determining $\mathrm{C}$ budgets, to feed and develop prediction models, and to handle soil conservation strategies at catchment scales (Liu et al., 2018). From previous works, in which the importance of soil disturbance in determining the way that OC associated with sediments is transported and deposited within the catchment were highlighted (Nadeu et al., 2011; Boix-Fayos et al., 2015), new research questions arose regarding the main stabilization mechanisms of this OC during transport and in several sedimentary deposits within the catchment. To answer these questions, here we take a step further, studying in depth how OC is mobilized across the catchment using a combination of physical and chemical organic matter fractionation techniques and comparing the different sedimentary deposits with three main sediment sources (forest and agricultural upland soils, fluvial lateral banks) to determine their relevance in OC sediment transport and deposition. Furthermore, we estimate basal respiration rates of upland soils, fluvial lateral banks, sediments in transit, and the different deposits. Combining information on the $\mathrm{OC}$ associated with soil aggregates and mineral particles, as an indicator of OC physicochemical protection, and basal respiration rates can shed light on whether OC is being accumulated or lost by erosion at the catchment scale. The main objective of this work was to evaluate the potential of the transport and depositional areas as sources or sinks of atmospheric $\mathrm{CO}_{2}$ in a subhumid Mediterranean catchment. The specific objectives 
were to (i) assess the changes in aggregate size distribution and associated OC in the sediments mobilized by soil erosion processes; (ii) identify the main stabilization mechanisms of OC in eroded soils and different sedimentary deposits; and (iii) determine the potential sources of eroded OC in the sedimentary deposits through the catchment. We performed the study in a sub-catchment $\left(111 \mathrm{~km}^{2}\right)$ in the headwaters of the Segura catchment in southeast Spain.

\section{Methods}

\subsection{Study area}

The study area is located in the headwaters of the Segura catchment (Murcia, southeast Spain), which drains to the Taibilla reservoir (Turrilla catchment) and is formed by three adjacent sub-catchments (Rogativa, Arroyo Blanco, and Arroyo Tercero) covering a total area of $111 \mathrm{~km}^{2}$ (Fig. 1a). The dominant lithology of the catchment consists of marls, limestones, marly limestones, and sandstones of the Cretaceous, Oligocene, and Miocene. The dominant soils in the area are Lithosols, Regosols, and Cambisols (IUSS Working Group WRB, 2015). The catchment is representative of the environmental conditions in Mediterranean mountainous areas of medium altitude. This catchment receives $530 \mathrm{~mm}$ of precipitation per year and has an average temperature of $13.5^{\circ} \mathrm{C}$. It has experienced important land use changes since the 1970s involving reforestation, including the construction of a dense network of check dams for hydrological and sediment control. Socioeconomic changes in the region resulted in the abandonment of agricultural activities and the recovery of the shrubland and forest. Nowadays, forests and shrublands represent approximately $80 \%$ of its area, while agricultural land represents $20 \%$. The hydrological and geomorphological effects of these catchment changes were studied in Boix-Fayos et al. (2008), Quiñonero-Rubio et al. (2016), and Pérez-Cutillas et al. (2018). The main fluvial course studied is ephemeral with water only flowing a few times per year during intense rain events. A deeper description of the study area is given in Boix-Fayos et al. (2015).

\subsection{Field experimental design and sampling}

The experimental design combines a fluvial geomorphological perspective and soil science analysis. Previous geomorphological analyses of the channel and adjacent areas and of the dynamics of the fluvial morphology in the last 60 years (Boix-Fayos et al., 2007; Nadeu et al., 2011) were used to identify the main sources and sinks of sediments in the Turrilla basin. This previous analysis was the background to the combination of the sediment cascade (Hoffman et al., 2013; Boix-Fayos et al., 2015) and the erosion cycle as the experimental approach (Fig. 1b). To accomplish it a sampling design was established (Fig. 1a, b, Table 1) that represented the following: (i) the eroding areas (source of sediments) and detachment phase; (ii) the transport areas (main channel) and the main transport processes (suspended sediments and bedload); and (iii) the depositional areas (along the channel and downstream), representing the sedimentary phase with medium-term depositional areas (alluvial wedges) and longterm depositional areas (reservoir sediments).

In each area and erosion phase, a representative number of samples was taken to cover the spatial variability of soils and sediments within the catchment. At each sampling point paired undisturbed (core of $100 \mathrm{~cm}^{3}$ ) and disturbed soil and sediment samples were collected for bulk density estimations and chemical analyses, respectively. All soil and sediment samples were stored in a freezer $\left(4^{\circ} \mathrm{C}\right)$ until they were processed for chemical analyses. A total of 89 samples were analyzed.

1. In eroding areas (Fig. 1a, b), representing the detachment phase of the erosion cycle, two sources of sediments were sampled: (i) surface soils under the two mainland uses of the catchment area (forest and agricultural land) and (ii) fluvial lateral banks well connected to the channel (Fig. 1b, Table 1). Surface soil $(0-10 \mathrm{~cm})$ samples were taken from different locations distributed from upstream to downstream in the catchment, representing the mainland uses and covers (highand low-density forests, pastures, shrublands, and croplands), but were finally pooled into two main groups: forest (less eroded) and agricultural soils. Fluvial banks (considered as subsoils) were sampled at an average depth of $80 \mathrm{~cm}$.

2. In transport areas, suspended sediments and bedload samples were collected in two fluvial reaches with different flow regimes, representing an ephemeral and a permanent stream. Suspended sediment samples were taken using a siphon sampler device designed to collect suspended sediment samples at different depths immediately after each flooding event (Dielh, 20018). Six samplers $(1 \mathrm{~L}$ bottles) were spaced vertically $(7.5 \mathrm{~cm}$ apart) and connected to an intake tube and an air vent. A limited number of samples, for which sufficient material was available to carry out all the analyses, were selected. The suspended sediment samples were taken over a period of 2 years. Moreover, the bedload in the fluvial bars and the channel of both ephemeral and permanent reaches were sampled at $0-10 \mathrm{~cm}$ of depth as representative of the bedload sediments, which are considered to be ephemeral at these dynamic positions. Both bare and vegetated fluvial bars were sampled in two periods of the year, representing dry and wet conditions.

3. At depositional sites, samples were taken at $0-40$ and at $40-80 \mathrm{~cm}$ depths in four alluvial wedges behind check dams that were installed in the catchment in the 1970s. These alluvial wedges had a depth of between 1 and 

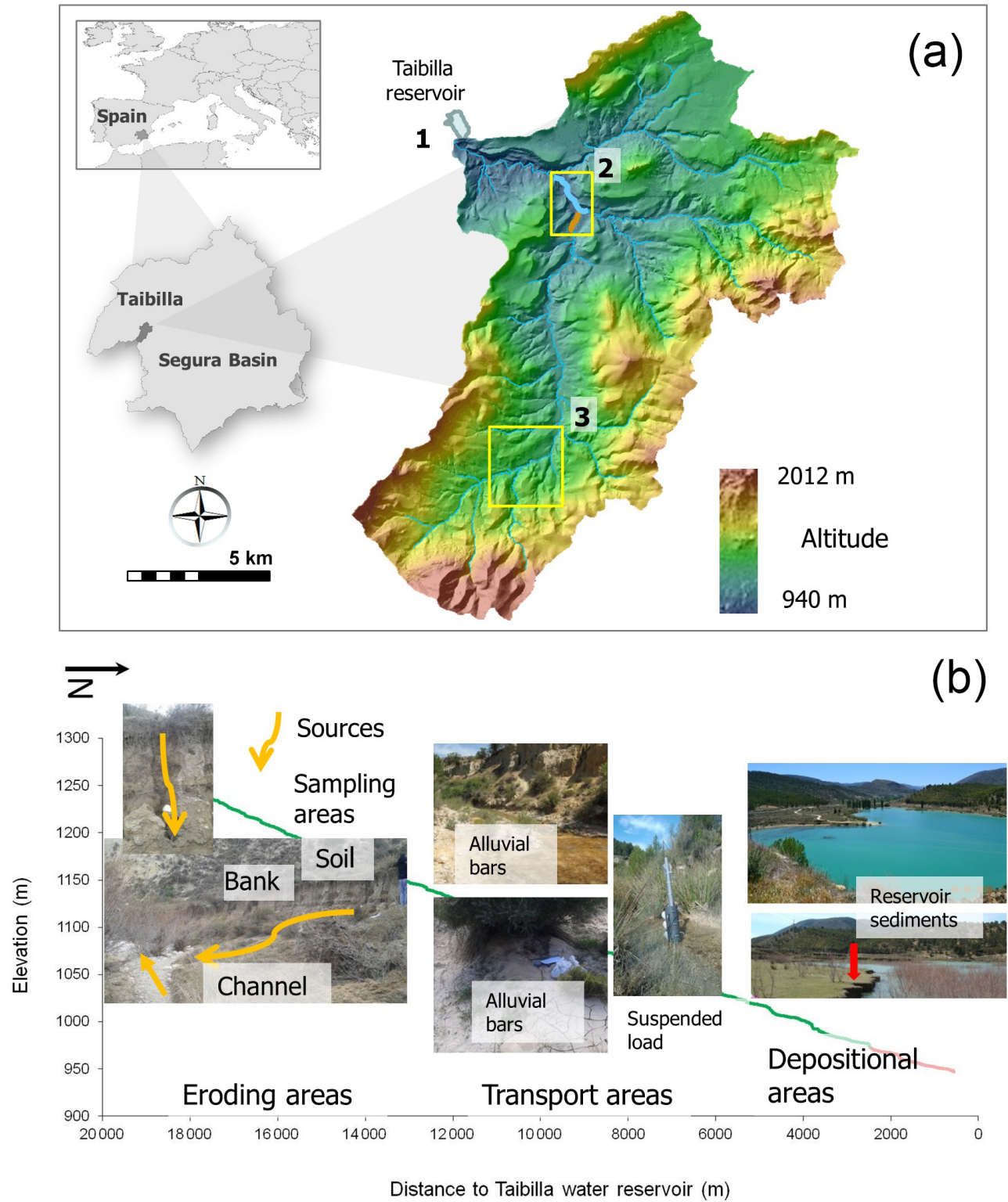

Figure 1. (a) Location of the Turrilla catchment and main sampling areas selected for sampling of soils and sediments. (1) The Taibilla reservoir at the outlet of the catchment (as representative of long-term depositional areas) where reservoir sediments were sampled; (2) permanent stream (in blue; Turrilla sub-catchment) and intermittent stream (in orange; Rogativa sub-catchment). In this area alluvial bars (as bedload), suspended load, soils, and lateral fluvial banks were sampled; (3) middle and upstream areas where forest soils and alluvial wedges (as representative of medium-term depositional areas behind check dams) were sampled. (b) Sediment cascade of the Turrilla catchment, with representation of sampling areas according to Table 1 . Please note that some depositional areas (mainly alluvial wedges behind check dams) were also sampled in the middle and upstream areas. Some soils were also sampled downstream.

$3 \mathrm{~m}$ and many of them were covered by vegetation. They were considered sedimentary areas of medium-term residence times. At the outlet of the catchment the reservoir sediments were sampled down to a depth of $3 \mathrm{~m}$ at several points. The different depths were pooled into surface layer $(0-40 \mathrm{~cm}$ depth) and deep layer $(40-300 \mathrm{~cm})$. These sediments were considered to have long-term res- idence times. The samples used in the analysis, and their depths, are shown in Table 1.

\subsection{Soil and sediment analyses}

\subsubsection{Water-stable soil aggregate size distribution}

Water-stable soil aggregate size separation was carried out using a modified wet-sieving method adapted from El- 
Table 1. Characteristics and representativeness of soil and sediment samples at the different morphological positions representing the different phases of the erosion process across the catchment.

\begin{tabular}{|c|c|c|c|c|}
\hline $\begin{array}{l}\text { Morphological } \\
\text { position }\end{array}$ & $\begin{array}{l}\text { Erosion } \\
\text { phase }\end{array}$ & $\begin{array}{l}\text { Sampling sites } \\
\text { or processes }\end{array}$ & $\begin{array}{r}\text { Depth } \\
(\mathrm{cm})\end{array}$ & $\begin{array}{r}\text { Sample } \\
(n)\end{array}$ \\
\hline \multirow{3}{*}{$\begin{array}{l}\text { Eroding areas } \\
\text { (sediment sources) }\end{array}$} & \multirow[t]{3}{*}{ Detachment } & Forest soils ${ }^{1}$ & $0-10$ & 9 \\
\hline & & Agricultural soils & $0-10$ & 4 \\
\hline & & Fluvial lateral bank & 80 & 5 \\
\hline \multirow{2}{*}{$\begin{array}{l}\text { Transport areas } \\
\text { (main channel) }\end{array}$} & \multirow[t]{2}{*}{ Transport } & Suspended load & Not applicable & 9 (five events) \\
\hline & & Bedload $^{2}$ & $0-10$ & 24 \\
\hline \multirow{4}{*}{$\begin{array}{l}\text { Depositional areas: } \\
\text { along the channel } \\
\text { and downstream }\end{array}$} & \multirow[t]{4}{*}{ Deposition } & Alluvial wedges & $0-40$ & 12 \\
\hline & & & $40-80$ & 4 \\
\hline & & & $0-40$ & 8 \\
\hline & & Reservoir & $40-300$ & 14 \\
\hline
\end{tabular}

${ }^{1}$ Includes a variety of soils representing the mainland covers in the catchment: forests, shrublands, and grasslands (three, four, and two samples, respectively). ${ }^{2}$ Includes alluvial bars and channel (18 and 6 samples, respectively).

liott (1986). Briefly, a $100 \mathrm{~g}$ sample of air-dried soil, disaggregated by hand, was placed on top of a $2000 \mu \mathrm{m}$ sieve and submerged for $5 \mathrm{~min}$ in deionized water at room temperature. The sieving was performed manually by moving the sieve up and down $3 \mathrm{~cm}, 50$ times in $2 \mathrm{~min}$, to achieve aggregate separation. Two sieves $(250$ and $63 \mu \mathrm{m})$ were used to obtain three aggregate classes: (i) $>250 \mu \mathrm{m}$ (macroaggregates; $\mathrm{M}$ ), (ii) $63-250 \mu \mathrm{m}$ (microaggregates; $\mathrm{m}$ ), and (iii) $<63 \mu \mathrm{m}$ (silt plus clay-sized particles; min). The aggregate size classes were oven-dried $\left(50^{\circ} \mathrm{C}\right)$, weighed, and stored in glass jars at room temperature $\left(21^{\circ} \mathrm{C}\right)$ (Fig. 2). From this, the mean weight diameter (MWD) was obtained as an indicator of aggregate stability.

Secondly, and in order to quantify the protected microaggregates contained within macroaggregates, the procedure described by Six et al. (2000) and Denef et al. (2004) was carried out (Fig. 2, square in green). A subsample (10 g) of the macroaggregates was immersed in deionized water on top of a $250 \mu \mathrm{m}$ mesh screen inside a cylinder. The macroaggregates were shaken together with 50 glass beads ( $4 \mathrm{~mm}$ diameter) until complete macroaggregate disruption was observed. Once the macroaggregates had been broken up, microaggregates and other material $<250 \mu \mathrm{m}$ passed through the mesh screen, with the help of a continuous water flow to the sieve. The material retained on the $63 \mu \mathrm{m}$ sieve (silt + clay; min) was wet-sieved to ensure that the isolated occluded microaggregates were water-stable (Six et al., 2000). These microaggregates obtained from macroaggregates $(\mathrm{Mm})$ were ovendried at $50^{\circ} \mathrm{C}(24 \mathrm{~h})$ in aluminum trays and weighed. The material retained on top of the $250 \mu \mathrm{m}$ mesh was considered the intra-aggregate particulate organic matter $\left(M_{\text {pom }}\right)$, representing the most labile fraction (active). It was separated and weighed after drying in an oven at $50^{\circ} \mathrm{C}$ (Fig. 2).

\subsubsection{Oxidation of mineral fractions}

The free and occluded mineral fractions $(<63 \mu \mathrm{m})$ obtained in steps 1 and 2 (Fig. 2) were oxidized by $\mathrm{NaOCl}$ to obtain a chemically resistant $\mathrm{C}$ fraction (rOC) (Zimmermann et al., 2007) representing the passive pool. A total of $1 \mathrm{~g}$ of every mineral fraction was oxidized for $18 \mathrm{~h}$ at $25^{\circ} \mathrm{C}$, with $50 \mathrm{~mL}$ of $6 \% \mathrm{NaOCl}$ adjusted to $\mathrm{pH} 8$ with concentrated $\mathrm{HCl}$. The oxidation residue was centrifuged at $1000 \mathrm{~g}$ for $15 \mathrm{~min}$, decanted, washed with deionized water, and centrifuged again. This oxidation step was repeated twice. The residue was dried at $50^{\circ} \mathrm{C}$ and weighed.

\subsubsection{Organic carbon and nitrogen analysis and pools ratios}

The OC and total nitrogen $(\mathrm{N})$ concentrations were determined separately for each water-stable aggregate size class and for the occluded microaggregates and occluded mineral fractions using an elemental analyzer (LECO TruSpec CN, Michigan, USA), after carbonate removal using $2 \mathrm{M} \mathrm{HCl}$. All the samples were analyzed in triplicate. When necessary, the OC concentration of each water-stable aggregate size class, as well as that of the intra-aggregate particulate organic matter (POM) and of the microaggregates occluded in the macroaggregates, was expressed on a sand-free aggregate basis (Elliott et al., 1991). The OC content was also expressed on a soil basis by multiplying the $\mathrm{C}$ concentration in each fraction by the weight proportion of that fraction:

$$
\begin{aligned}
& \text { OC content }\left(\mathrm{g} \mathrm{OC} \mathrm{kg}^{-1} \text { soil }\right)=(\mathrm{OC})_{\text {fraction }} \\
& \quad \times(\text { proportion of the fraction })_{\text {soil }},
\end{aligned}
$$

where $(\mathrm{OC})_{\text {fraction }}$ is the $\mathrm{OC}$ concentration in each fraction and (proportion of the fraction) soil $_{\text {in }}$ is the percentage of the OC that each fraction represents in the bulk soil. The same 


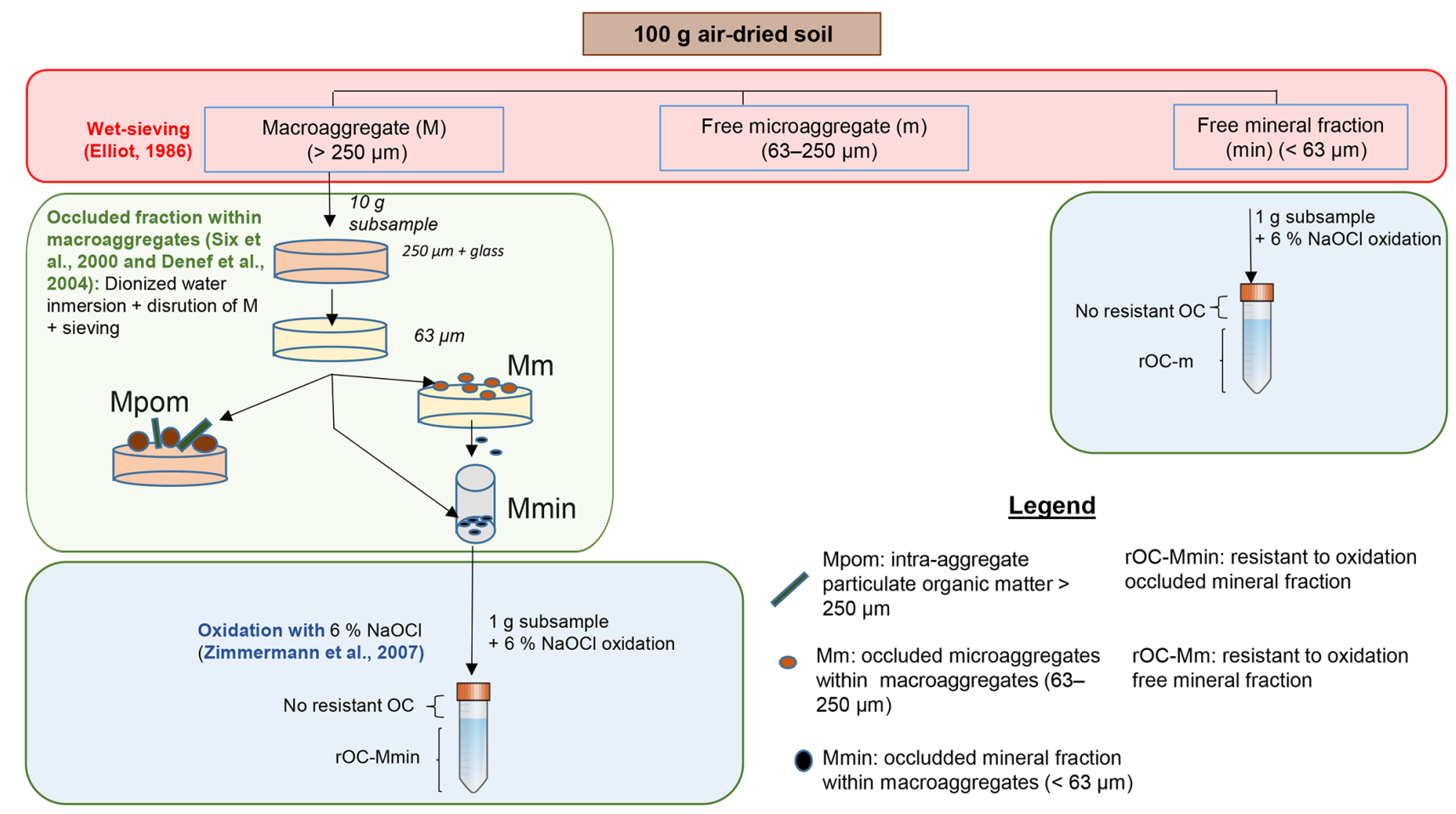

Figure 2. Description of the main steps and physicochemical analysis (wet-sieving and oxidation) used to obtain the different aggregate size fractions (square in red), the intra-aggregate organic matter, the occluded microaggregates and the occluded mineral fractions within macroaggregates (square in green), and fractions resistant to oxidation (square in blue).

procedure was followed to analyze total $\mathrm{N}$ in each of the separated fractions.

The total OC and total $\mathrm{N}$ in the bulk soil were considered as the sum of the $\mathrm{OC}$ or total $\mathrm{N}$ in each separated water-stable aggregate size fraction.

$$
\begin{aligned}
& \text { Total OC }(\text { or total } \mathrm{N})=\text { macroaggregate }(\mathrm{M}) \\
& + \text { microaggregate }(\mathrm{m})+\text { mineral fraction }(\mathrm{min})
\end{aligned}
$$

In addition, we used the macroaggregate stabilization ratio as an indicator of the physicochemical stabilization of OC in macroaggregates (OC occluded in microaggregates and occluded in mineral particles, compared to that associated with the intra-aggregate particulate organic matter fraction, based on the macroaggregate turnover index by Six et al., 2000):

\section{Stabilized OC in macroaggregates}

$$
=(\mathrm{OC}-\mathrm{Mm}+\mathrm{OC}-\mathrm{Mmin}) /\left(\mathrm{OC}-\mathrm{M}_{\mathrm{pom}}\right),
$$

where OC-Mm and OC-Mmin refer to the OC associated with the occluded microaggregates and the mineral fraction, respectively, and OC- $M_{\text {pom }}$ refers to the OC associated with the intra-aggregate particulate organic matter fraction. The higher the ratio, the more stabilized the $\mathrm{OC}$ is within macroaggregates (Fig. 2).

\subsection{Soil and sediment incubations}

Soils and sediments were incubated under controlled aerobic conditions for 32 days while keeping moisture (at $60 \%$ of the water-holding capacity) and temperature $\left(28^{\circ} \mathrm{C}\right)$ constant to estimate their potential OC mineralization rates ( $\mathrm{mg} \mathrm{CO}_{2} \mathrm{~kg}^{-1}$ soil or sediment). Thus, optimal conditions for microbial activity were mimicked in order to induce the (natural) potential maximum heterotrophic $\mathrm{CO}_{2}$ soil respiration, following the approach adopted by other authors (Paul et al., 2001; Doetterl et al., 2012). We incubated three replicate samples of $30 \mathrm{~g}$ of fresh soil and sediment material that was prepared for fractionation from the different areas throughout the catchment and at different depth intervals (see Table 1). Previously, the maximum water-holding capacity for each sample was estimated in triplicate, following the procedure of Howard and Howard (1993). Each sample was put in a hermetically sealed flask $(125 \mathrm{~mL})$ with no further additives. The $\mathrm{CO}_{2}$ released was measured periodically (every day for the first 4 days, every 3 days during the second week, and then weekly) using an infrared gas analyzer (CheckmateII, PBI Dansensor, Denmark), and the flasks were opened for $30 \mathrm{~min}$ after each measurement to avoid the accumulation of $\mathrm{CO}_{2}$. The moisture content of the samples was also checked periodically, but replacement of the evaporated water was not necessary during the experiment. We used linear interpolations between sampling dates 
and then summed them across all dates to estimate the cumulative amount of $\mathrm{CO}_{2}$ released (mineralized) after 32 days of incubation; basal soil or sediment respiration was expressed as $\mathrm{mg} \mathrm{CO} 2-\mathrm{C} \mathrm{kg}^{-1}$ soil per day.

\subsection{Statistical analysis}

Statistical tests to detect differences between the means of the sediment sources and sinks - representative of the eroding, transport, and deposition phases of the erosion process were performed separately for each erosion phase and depth (when applicable) using the nonparametric Kruskal-Wallis test for independent measurements. This nonparametric test was used because the sampling design was not balanced due to the different number of samples $(n)$ in the eroding, transport, and depositional areas (Table 1). Significant differences were identified at the 0.05 probability level of significance. Spearman correlations were performed to explore the relationships between most of the studied variables within each erosion phase. All statistical analyses were carried out using SPSS 24.0 (SPSS Inc., Chicago, IL, USA).

\section{Results}

\subsection{Water-aggregate size distribution and associated OC: $M, \mathrm{~m}$, and min}

Eroding areas. On average, the forest soils had the highest percentage of total macroaggregates (M) and MWD values (Table 2) when compared to the agricultural soils and fluvial lateral banks. The agricultural soils and fluvial lateral banks showed the same distribution trend - a decrease in the percentage of aggregates with increasing aggregate size - while in the forest soils a predominance of macroaggregates existed (Fig. 3a).

The forest soils also showed the highest content of OC associated with the macroaggregates (OC-M), followed by the agricultural soils. The agricultural soils showed higher OC in macroaggregates than the fluvial lateral banks, despite their lower percentage of macroaggregates (Fig. 3a, b). A decrease in OC with decreasing aggregate size was found in the forest and agricultural soils, while no differences in the OC associated with different aggregate sizes were observed in the fluvial lateral banks (Fig. 3b).

Transport areas. A higher percentage of total macroaggregates and higher MWD, but a lower percentage of free mineral particles, were observed in the bedload in comparison with the suspended sediments (Table 2). However, the suspended sediments had a higher OC-M content, while the OC content in the free mineral fraction (OC-min) was similar between the two types of transport sediment (Fig. 3a, b). In addition, for the suspended sediments the distribution of aggregates $(\min >\mathrm{m}>\mathrm{M})$ and the $\mathrm{OC}$ associated with the largest aggregates (OC-M) were similar to that of the agricultural soils.
Depositional areas. In the alluvial wedges, the free mineral fraction predominated over the macroaggregates and microaggregates, regardless of depth. The opposite was observed when considering the OC content associated with these fractions, the order being OC-M $>$ OC-m $>$ OC-min (Fig. 3a, b), similar to the trend in the forest and agricultural soils. In addition, a decrease in the percentage of macroaggregates from the upper to the deepest layer of the alluvial wedges was found. For the reservoir sediments, the percentage of macroaggregates and the OC-M content were highest in the upper layer, while the free mineral fraction represented the highest percentages among the distinct fractions in the deep sediment layers and had the highest percentages across the catchment (Fig. 3a, b).

\subsection{Intra-aggregate particulate organic matter, occluded microaggregates, and occluded mineral fraction within macroaggregates and associated OC: $M_{\text {pom }}, M m$, and Mmin}

Eroding areas. The $M_{\text {pom }}$ fraction represented about $14 \%$ of the total in the forest soil, followed by the fluvial lateral banks and agricultural soils (lower than $5 \%$ ). The associated OC content in the $M_{\text {pom }}\left(\mathrm{OC}-M_{\text {pom }}\right)$ oscillated between $3 \%$ and $0.61 \%$, decreasing in the following order: forest soils $>$ agricultural soils $>$ fluvial lateral banks (Fig. 4a, b). Although no clear differences were observed in the percentages of $\mathrm{Mm}$ and Mmin among the sediment sources (due to high spatial variability), the contents of OC-Mm and OC-Mmin were highest in the forest soils (Fig. 4b).

Transport areas. The percentage of the $M_{\text {pom }}$ fraction in the sediments in transit (suspended and bedload sediments) was about $10 \%$. The OC- $M_{\text {pom }}$ content in the suspended sediments and in the bedload sediments was similar and lower, respectively, when compared to those of the soils and fluvial lateral banks (Fig. 4b). The sediments in transit displayed a significant decrease (about 50\%) in the Mm and Mmin percentages as well as in the $\mathrm{OC}$ associated with these fractions (OC-Mm and OC-Mmin) with respect to the forest soils. However, sediments in transit showed a lower percentage of Mm but similar OC-Mm and OC-Mmin contents compared to the agricultural soils and fluvial lateral banks (Fig. 4a, b).

Depositional areas. In the upper sediment layer of the reservoir the percentage of the $M_{\text {pom }}$ fraction was higher and the OC- $M_{\text {pom }}$ content was lower than those of the alluvial wedges (Fig. 4b). In the upper sediment layer of the alluvial wedges the OC- $M_{\text {pom }}$ content was higher compared to the forest and agricultural soils (Fig. 4b), while the opposite happened at the reservoir. In addition, the OC- $M_{\text {pom }}$ content decreased with depth in both depositional areas, although this decrease was more pronounced in the case of the alluvial wedges sediments (Fig. 4b). The percentages of occluded microaggregates $(\mathrm{Mm})$ at the reservoir, and of the occluded mineral fraction (Mmin) in the alluvial wedges, were higher than in the eroding areas (forest and agricultural soils and 

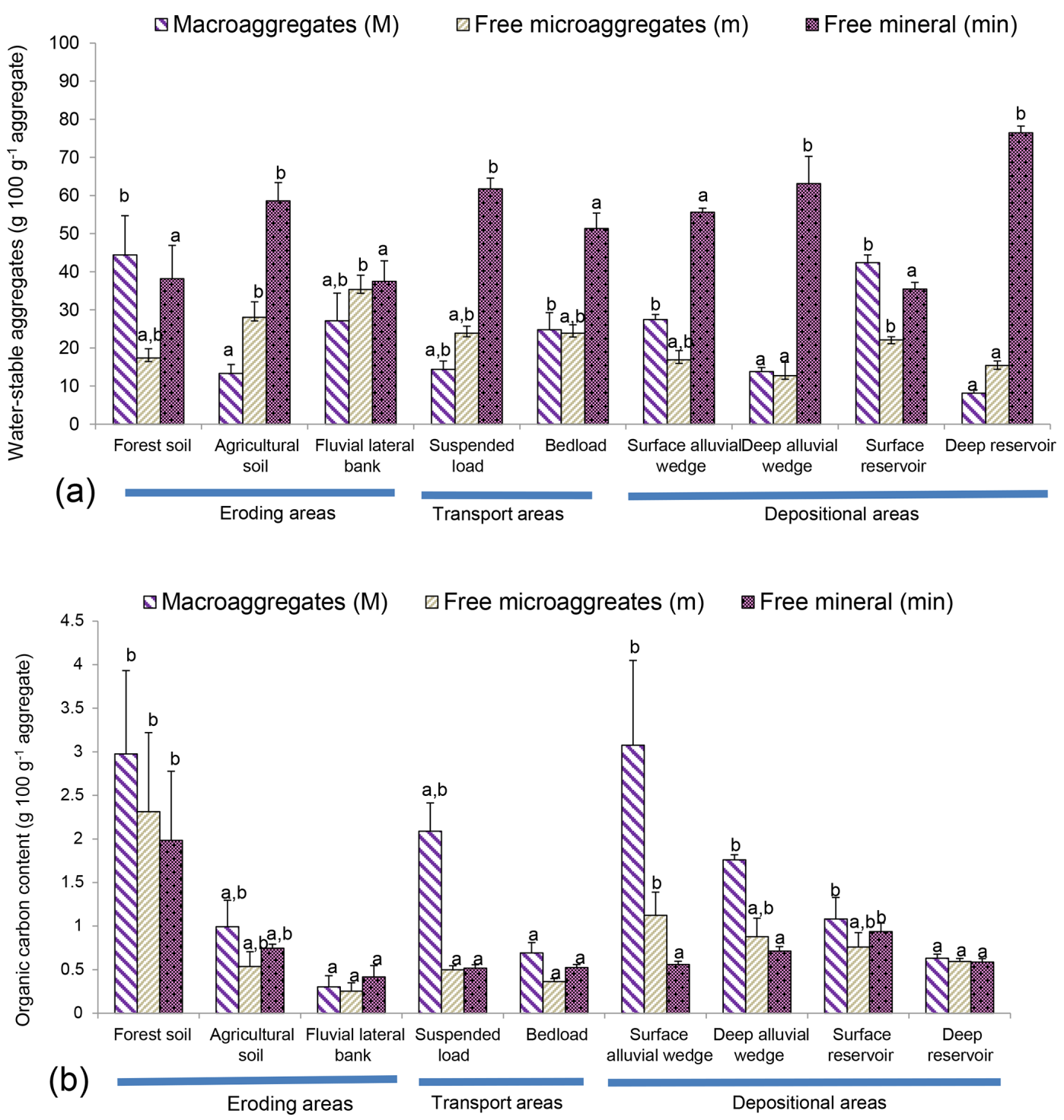

Figure 3. (a) Water-stable aggregate size distribution (g aggregate $100 \mathrm{~g}^{-1}$ soil) for $>250 \mu \mathrm{m}$ (macroaggregates: $\mathrm{M}$ ), $63-250 \mu \mathrm{m}$ (free microaggregates, $\mathrm{m}$ ), and $<63 \mu \mathrm{m}$ (free mineral fraction: $\mathrm{min}$ ) in different geomorphological positions within the catchment: eroding, transport, and depositional areas. Numeral values are means \pm SE. Bars with different lowercase letters indicate significant differences in the percentage of each water-stable aggregate size among the different soils and sediments $(p<0.05)$ according to the Kruskal-Wallis test. (b) Organic carbon content (g $100 \mathrm{~g}^{-1}$ aggregate) for $>250 \mu \mathrm{m}$ (macroaggregates: $\left.\mathrm{M}\right), 63-250 \mu \mathrm{m}$ (free microaggregates, $\mathrm{m}$ ), and <63 $\mu \mathrm{m}$ (free mineral fraction: $\mathrm{min}$ ) in different geomorphological positions within the catchment: eroding, transport, and depositional areas. Numeral values are means \pm SE. Bars with different lowercase letters indicate significant differences in the percentage of each water-stable aggregate size among the different soils and sediments $(p<0.05)$ according to the Kruskal-Wallis test.

fluvial lateral banks) (Fig. 4a). However, both types of sedimentary deposit had slightly lower OC contents associated with these occluded fractions (OC-Mm and OC-Mmin) than the forest soils, but the values were similar to those obtained in the agricultural soils and fluvial lateral banks (Fig. 4a, b).

The percentage of the total Mm and Mmin decreased significantly with depth in both depositional areas, being more pronounced in the case of the reservoir, where the Mm percentage in the deep sediment layer was reduced up to $75 \%$ when compared to that in the upper sediment layer (Fig. 4a). The alluvial wedges had a higher OC-Mm content in the upper sediment layer, and higher OC-Mm and OC-Mmin contents in the deep sediment layer, compared to the reservoir (Fig. 4b).

\subsection{OC quality}

The contents of free and occluded mineral fraction resistant to $\mathrm{NaClO}$ oxidation, denoted as rOC-min and rOC-Mmin, 
Table 2. Soil texture, MWD, and total organic carbon (OC) in different morphological positions across the catchment: eroding, transport, and depositional areas.

\begin{tabular}{|c|c|c|c|c|c|}
\hline \multirow{2}{*}{$\begin{array}{l}\text { Morphological } \\
\text { positions }\end{array}$} & \multicolumn{3}{|c|}{ Texture $(\%)$} & \multirow{2}{*}{$\begin{array}{l}\text { MWD } \\
(\mathrm{mm})\end{array}$} & \multirow{2}{*}{$\begin{array}{l}\text { Total OC } \\
\left(\mathrm{g} \mathrm{kg}^{-1}\right)\end{array}$} \\
\hline & Clay & Silt & Sand & & \\
\hline Forest soil & $17.1 \pm 1.9^{b}$ & $51.9 \pm 3.8^{\mathrm{a}, \mathrm{b}, \mathrm{c}}$ & $30.1 \pm 5.72^{b}$ & $0.96 \pm 0.26^{\mathrm{c}}$ & $22.1 \pm 8.9^{b}$ \\
\hline Agricultural soil & $18.9 \pm 3.2^{\mathrm{b}}$ & $58.6 \pm 8.5^{\mathrm{b}, \mathrm{c}}$ & $22.4 \pm 11.1^{\mathrm{b}}$ & $0.26 \pm 0.05^{\mathrm{b}}$ & $6.8 \pm 0.9^{\mathrm{b}}$ \\
\hline Fluvial lateral bank & $15.9 \pm 3.5^{\mathrm{b}}$ & $43.2 \pm 7.3^{\mathrm{b}}$ & $38.2 \pm 10.0^{\mathrm{b}}$ & $0.39 \pm 0.08^{\mathrm{b}}$ & $3.4 \pm 1.07^{\mathrm{a}}$ \\
\hline Eroding areas & $17.2 \pm 1.5^{\mathrm{B}}$ & $50.9 \pm 3.4^{\mathrm{A}}$ & $30.6 \pm 4.5^{\mathrm{A}, \mathrm{B}}$ & $0.63 \pm 0.2^{\mathrm{B}}$ & $13.4 \pm 4.8^{\mathrm{B}}$ \\
\hline Suspended load & $34.1 \pm 5.55^{\mathrm{c}}$ & $61.7 \pm 4.8^{\mathrm{c}}$ & $4.0 \pm 1.47^{\mathrm{a}}$ & $0.22 \pm 0.04^{\mathrm{b}, \mathrm{a}}$ & $7.5 \pm 0.5^{b}$ \\
\hline Bedload & $9.9 \pm 0.6^{\mathrm{a}}$ & $39.1 \pm 2.3^{\mathrm{a}}$ & $50.4 \pm 2.9^{c}$ & $0.41 \pm 0.05^{\mathrm{c}, \mathrm{b}}$ & $4.3 \pm 0.3^{\mathrm{a}}$ \\
\hline Transport areas & $16.5 \pm 2.4^{\mathrm{A}}$ & $45.2 \pm 2.7^{\mathrm{A}}$ & $37.7 \pm 4.2^{\mathrm{B}}$ & $0.39 \pm 0.04^{\mathrm{A}}$ & $5.2 \pm 0.3^{\mathrm{A}}$ \\
\hline Alluvial wedge surface & $10.9 \pm 0.4^{\mathrm{a}}$ & $69.2 \pm 1.9^{\mathrm{c}}$ & $19.8 \pm 2.17^{\mathrm{b}}$ & $0.73 \pm 0.04^{\mathrm{c}}$ & $12.8 \pm 1.8^{\mathrm{b}}$ \\
\hline Alluvial wedge deep & $14.9 \pm 1.9^{\mathrm{a}, \mathrm{b}}$ & $76.0 \pm 3.2^{\mathrm{c}}$ & $8.9 \pm 1.49^{\mathrm{a}}$ & $0.23 \pm 0.02^{b}$ & $7.6 \pm 0.5^{\mathrm{a}}$ \\
\hline Alluvial wedges & $11.9 \pm 0.7^{\mathrm{A}}$ & $70.9 \pm 1.7^{\mathrm{B}}$ & $17.1 \pm 2.04^{\mathrm{A}}$ & $0.60 \pm 0.06^{\mathrm{B}}$ & $11.5 \pm 1.4^{\mathrm{B}}$ \\
\hline Reservoir surface & $14.7 \pm 0.8^{b}$ & $60.6 \pm 0.9^{\mathrm{b}, \mathrm{c}}$ & $24.6 \pm 1.2^{b}$ & $0.76 \pm 0.45^{\mathrm{c}}$ & $9.26 \pm 1.16^{b}$ \\
\hline Reservoir deep & $18.0 \pm 0.9^{b}$ & $61.9 \pm 0.9^{c}$ & $20.0 \pm 1.8^{\mathrm{b}}$ & $0.14 \pm 0.01^{\mathrm{a}}$ & $5.9 \pm 0.4^{\mathrm{a}, \mathrm{b}}$ \\
\hline Reservoir & $16.8 \pm 0.7^{\mathrm{B}}$ & $61.5 \pm 0.7^{\mathrm{A}}$ & $21.7 \pm 1.3^{\mathrm{A}, \mathrm{B}}$ & $0.37 \pm 0.06^{\mathrm{A}}$ & $7.1 \pm 0.6^{\mathrm{A}, \mathrm{B}}$ \\
\hline
\end{tabular}

Numeral values are means \pm SE. Columns with different lowercase letters indicate significant differences among sites or processes. Columns with different uppercase letters mean significant differences between big pooled groups $(p<0.05)$, according to the Kruskal-Wallis test.

respectively, were higher in the forest and agricultural soils than in the fluvial lateral banks, with values ranging from $0.55 \%$ to $0.13 \%$. Interestingly, the rOC-min in the suspended sediments was comparable to that in the forest and agricultural soils and was lower than that in the bedload sediments, which displayed contents similar to those of the fluvial lateral banks (Table 3). It is noteworthy that the rOC was higher in the occluded fraction than in the free mineral fraction in the lateral fluvial bank, bedload, and deep layer of the reservoir (Table 3).

The degree of physicochemical stabilization of the $\mathrm{OC}$ in macroaggregates $-(\mathrm{OC}-\mathrm{Mm}+\mathrm{OC}-\mathrm{Mmin}) / \mathrm{OC}-M_{\mathrm{pom}}-$ could be divided into three groups: (i) the reservoir, showing the highest ratios (more stabilized); (ii) the soils and fluvial lateral banks, bedload sediments, and alluvial wedges, with medium ratios; and (iii) the suspended sediments, with the lowest value (less stabilized) (Table 4).

The basal respiration (BR) rates ranged between 0.81 and $6.04 \mathrm{mg} \mathrm{CO}_{2} \mathrm{~kg}^{-1} \mathrm{day}^{-1}$ in the eroding sources, with the lowest values occurring in the fluvial lateral banks (Table 4). In the sedimentary deposits, BR ranged from 0.70 to $13.8 \mathrm{mg}$ $\mathrm{CO}_{2} \mathrm{~kg}^{-1}$ day $^{-1}$, with the values being highest in the upper sediment layers of the alluvial wedges and lowest in the deep layer of the reservoir. In the transport areas, the suspended sediments had higher respiration rates than the bedload sediments, being the second-highest rate observed through the catchment (Table 4).

Higher $\mathrm{C}: \mathrm{N}$ ratios were found in the upper sediment layers of the alluvial wedges, forest soils, and suspended sediments. A decrease in the $\mathrm{C}: \mathrm{N}$ ratio with increasing depth occurred in soils and sediments of the alluvial wedges, but no changes with depth were observed at the reservoir (Table 4).

\subsection{Correlations between the different physical, chemical, and biological variables}

Positive correlations among the labile fraction, OC- $M_{\text {pom }}$, and the total OC associated with macroaggregates (OC-M) were observed in all areas. However, correlations among OC$M_{\text {pom }}$ and the macroaggregates (M), micro within macroaggregate $(\mathrm{Mm})$ percentage, and OC-Mm content were found in the eroding and depositional areas but not in transport areas. Moreover, in the eroding and depositional areas (the reservoir), positive correlations were obtained between OC$M_{\text {pom }}$ and the oxidable occluded OC (Table 5). The BR was highly and positively correlated with the OC- $M_{\text {pom }}$ content in eroding and depositional areas but not in transport areas. On the other hand, negative correlations between BR and the OC stabilized in macroaggregates $(r=-0.40 ; p=0.01)$ across the study areas were obtained. 

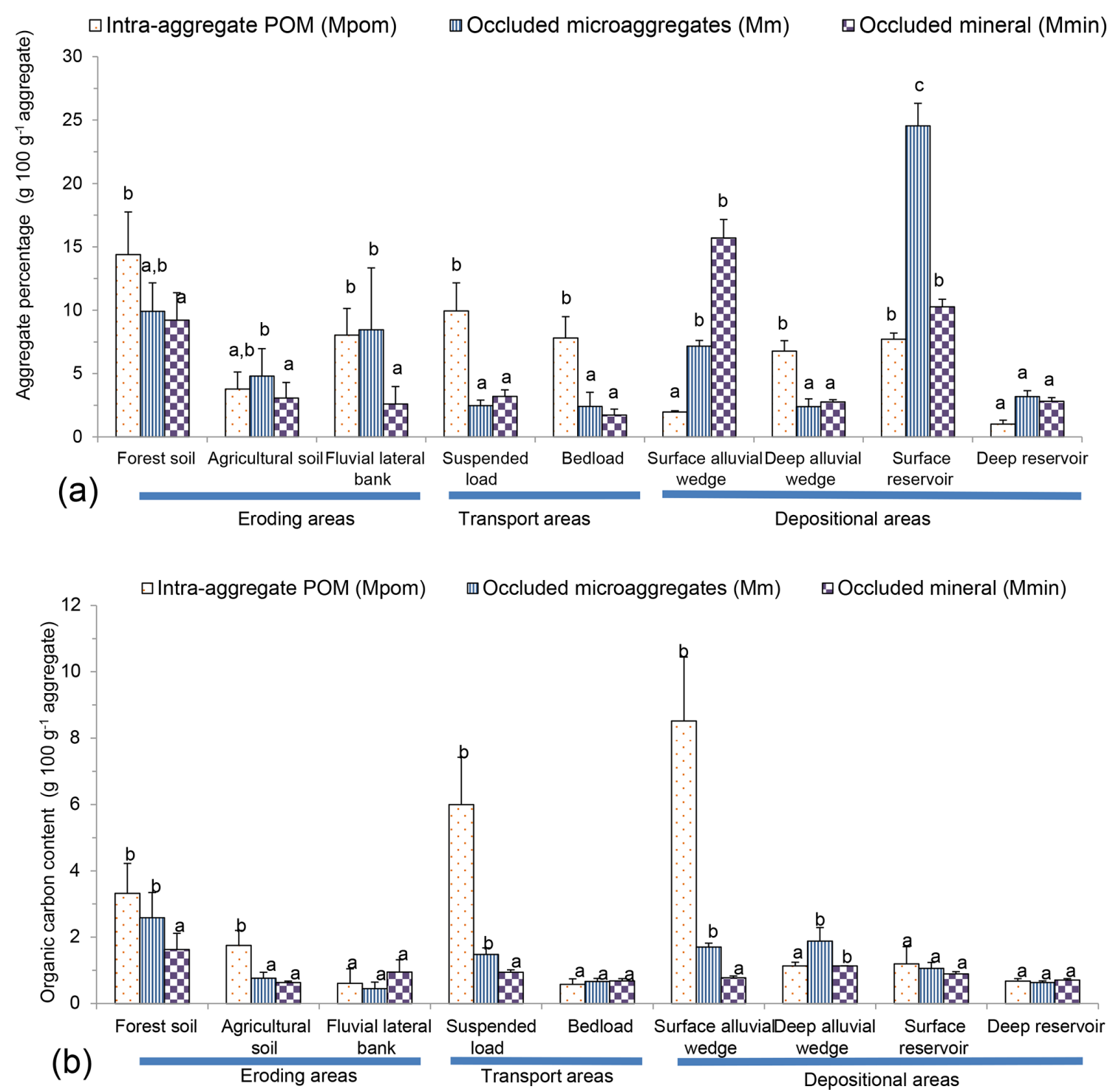

Figure 4. (a) Weight percentage (g $100 \mathrm{~g}^{-1}$ aggregate) of the fractions occluded within macroaggregates (M) for intra-aggregate particulate organic matter $\left(M_{\mathrm{pom}}\right)$, occluded microaggregates $(\mathrm{Mm})$, and occluded mineral fraction (Mmin) in different geomorphological positions within the catchment: eroding, transport, and depositional areas. Numeral values are means \pm SE. Bars with different lowercase letters indicate significant differences in the percentage of each water-stable aggregate size among the different soils and sediments $(p<0.05)$ according to the Kruskal-Wallis test. (b) Organic carbon content (g $100 \mathrm{~g}^{-1}$ aggregate) associated to the occluded fractions within total macroaggregates $(\%)$ for intra-aggregate particulate organic matter $\left(M_{\text {pom }}\right)$, occluded microaggregates $(\mathrm{Mm})$, and occluded mineral fraction (Mmin) in different geomorphological positions within the catchment: eroding, transport, and depositional areas. Numeral values are means \pm SE. Bars with different lowercase letters indicate significant differences in the percentage of each water-stable aggregate size among the different soils and sediments $(p<0.05)$ according to the Kruskal-Wallis test.

\section{Discussion}

\subsection{Dynamics of $\mathrm{OC}$ in the eroding areas}

The differences among the sources of the sediments, in terms of aggregation and OC distribution within aggregates, determined the way in which the sediment and associated OC moved across the catchment, which is in line with results given by some authors reporting that aggregation consider- ably reduces the potential transport distance of eroded OC and hence potentially skews its redistribution in watersheds towards terrestrial deposition (Hu et al., 2016).

The distribution of OC within aggregates (the OC content increased with increasing aggregate size) observed in the forest soils, together with the high percentage of occluded microaggregates within macroaggregates $(\mathrm{Mm})$, rich in OC indicates a hierarchical order of aggregation in which 
Table 3. OC resistant to $\mathrm{NaOCl}$ oxidation in the free mineral fraction (rOC-min) and occluded mineral fraction (rOC-Mmin); contribution of rOC-min and rOC-Mmin to the total mineral fraction in the different morphological positions across the catchment: eroding, transport, and depositional areas.

\begin{tabular}{|c|c|c|c|c|}
\hline & \multicolumn{4}{|c|}{ OC resistant to $\mathrm{NaOCl}$ oxidation } \\
\hline & rOC-min & rOC-Mmin & rOC-min & rOC-Mmin \\
\hline & \multicolumn{2}{|c|}{ g $100 \mathrm{~g}^{-1}$ aggregate } & \multicolumn{2}{|c|}{$\begin{array}{l}\text { Contribution to the total } \\
\text { mineral fraction }(\%)\end{array}$} \\
\hline \multicolumn{5}{|l|}{ Eroding } \\
\hline Forest soil & $0.55 \pm 0.25^{\mathrm{b}}$ & $0.35 \pm 0.11^{\mathrm{b}}$ & $15.33 \pm 4.5$ & $3.58 \pm 1.25$ \\
\hline Agricultural soil & $0.29 \pm 0.01^{\mathrm{b}}$ & $0.29 \pm 0.01^{\mathrm{b}}$ & $28.87 \pm 2.6$ & $1.24 \pm 0.53$ \\
\hline Fluvial lateral bank & $0.13 \pm 0.02^{\mathrm{aA}}$ & $0.29 \pm 0.03^{\mathrm{bB}}$ & $40.04 \pm 21.22$ & $12.17 \pm 8.03$ \\
\hline \multicolumn{5}{|l|}{ Transport } \\
\hline Suspended load & $0.21 \pm 0.1^{\mathrm{b}}$ & $0.31 \pm 0.02^{b}$ & $24.24 \pm 11.47$ & $1.44 \pm 1.35$ \\
\hline Bedload & $0.13 \pm 0.02^{\mathrm{aA}}$ & $0.22 \pm 0.02^{\mathrm{bB}}$ & $18.71 \pm 3.01$ & $0.72 \pm 0.15$ \\
\hline \multicolumn{5}{|l|}{ Deposition } \\
\hline Alluvial wedge surface & $0.23 \pm 0.04^{\mathrm{b}}$ & $0.29 \pm 0.02^{b}$ & $27.55 \pm 6.49$ & $1.56 \pm 0.41$ \\
\hline Alluvial wedge deep & $0.17 \pm 0.04^{\mathrm{b}}$ & $0.29 \pm 0.01^{\mathrm{b}}$ & $20.76 \pm 7.33$ & $1.22 \pm .05$ \\
\hline Reservoir surface & $0.19 \pm 0.04^{\mathrm{b}}$ & $0.26 \pm 0.02^{b}$ & $16.92 \pm 1.39$ & $2.01 \pm 0.41$ \\
\hline Reservoir deep & $0.12 \pm 0.01^{\mathrm{aA}}$ & $0.16 \pm 0.001^{\mathrm{aB}}$ & $11.93 \pm 0.94$ & $0.62 \pm 0.09$ \\
\hline
\end{tabular}

Numeral values are means \pm SE. Columns with different lowercase letters indicate significant differences among sites or processes $(p<0.05)$ according to the Kruskal-Wallis test. Rows with different capital letters mean significant differences between OC fractions within each site or process.

Table 4. $\mathrm{C}: \mathrm{N}$ ratios, basal respiration rate, and indicators of OC stabilized in macroaggregates $\left(\mathrm{OC}-\mathrm{Mm}+\mathrm{OC}-\mathrm{Mmin} / \mathrm{OC}-M_{\mathrm{pom}}\right)$ in the different morphological positions across the catchment: eroding, transport, and depositional areas.

\begin{tabular}{|c|c|c|c|}
\hline & $\begin{array}{l}\mathrm{C}: \mathrm{N} \\
\text { Ratio }\end{array}$ & $\begin{array}{l}\text { Basal respiration } \\
\left(\mathrm{mg} \mathrm{CO}_{2}-\mathrm{kg}^{-1}\right. \\
\text { soil sed } \\
\left.\text { day }^{-1}\right)\end{array}$ & $\begin{array}{l}\text { OC stabilized in } \\
\text { macroaggregates }\end{array}$ \\
\hline \multicolumn{4}{|l|}{ Eroding areas } \\
\hline Forest soil & $12.1 \pm 1.2^{\mathrm{b}}$ & $6.04 \pm 1.74^{\mathrm{b}, \mathrm{c}}$ & $0.88 \pm 0.3^{\mathrm{b}}$ \\
\hline Agricultural soil & $8.8 \pm 0.7^{\mathrm{a}, \mathrm{b}}$ & $2.59 \pm 0.29^{\mathrm{b}, \mathrm{c}}$ & $1.22 \pm 0.7^{\mathrm{b}}$ \\
\hline Fluvial lateral bank & $9.5 \pm 2.8^{\mathrm{a}}$ & $0.81 \pm 0.18^{\mathrm{a}}$ & $1.09 \pm 0.4^{b}$ \\
\hline \multicolumn{4}{|l|}{ Transport areas } \\
\hline Suspended load & $10.6 \pm 1.3^{b}$ & $6.94 \pm 0.77^{\mathrm{c}}$ & $0.44 \pm 0.2^{\mathrm{a}}$ \\
\hline Bedload & $8.2 \pm 0.5^{\mathrm{a}}$ & $3.25 \pm 0.53^{b}$ & $0.98 \pm 0.2^{b}$ \\
\hline \multicolumn{4}{|l|}{ Depositional areas } \\
\hline Alluvial wedge surface & $13.4 \pm 1.6^{\mathrm{b}}$ & $13.80 \pm 1.04^{\mathrm{c}}$ & $0.82 \pm 0.1^{\mathrm{b}}$ \\
\hline Alluvial wedge deep & $8.4 \pm 2.1^{\mathrm{a}}$ & $2.83 \pm 1.04^{\mathrm{a}, \mathrm{b}}$ & $1.40 \pm 0.3^{\mathrm{b}}$ \\
\hline Reservoir surface & $8.5 \pm 0.6^{\mathrm{a}}$ & $4.58 \pm 1.47^{\mathrm{b}}$ & $5.53 \pm 2.8^{\mathrm{c}}$ \\
\hline Reservoir deep & $8.9 \pm 2.3^{\mathrm{a}}$ & $0.70 \pm 0.02^{\mathrm{a}}$ & $11.47 \pm 1.8^{\mathrm{c}}$ \\
\hline
\end{tabular}

Numeral values are means \pm SE. Columns with different lowercase letters indicate significant differences among sites or processes $(p<0.05)$ according to the Kruskal-Wallis test. * The higher the value the more stabilized the $\mathrm{OC}$ in macroaggregates.

macroaggregates are the nucleus for microaggregate formation (Oades, 1984). Other authors (Sodhi et al., 2009; Wang et al., 2011) also reported a higher OC content in macroag- gregates than in microaggregates in soils, which means that organic matter could be the major binding agent in such soils (Oades and Waters, 1991). Here, the agricultural soils 
Table 5. Spearman correlation coefficients between the OC associated with intra-aggregate POM (OC- $M_{\text {pom }}$ ) or basal respiration (BR) and aggregate percentage and associated total $\mathrm{OC}, \mathrm{MWD}$, occluded oxidable $\mathrm{OC}, \mathrm{CN}$ ratios, and OC stabilized in macroaggregates in the different geomorphological positions within the catchment: eroding, transport, and depositional areas.

\begin{tabular}{|c|c|c|c|c|}
\hline \multirow[t]{2}{*}{ OC- $M_{\text {pom }}\left(\mathrm{g} \mathrm{kg}^{-1}\right.$ soil sed $\left.^{-1}\right)$} & \multirow[t]{2}{*}{ Eroding areas } & \multirow[t]{2}{*}{ Transport areas } & \multicolumn{2}{|c|}{ Depositional areas } \\
\hline & & & Alluvial wedges & Reservoir \\
\hline Macroaggregates $(\%)$ & $0.82^{* *}$ & 0.04 & 0.23 & $0.77^{* *}$ \\
\hline Micro within macro (\%) & 0.52 & 0.39 & 0.04 & 0.27 \\
\hline OC macroaggregates $\left(\mathrm{g} \mathrm{kg}^{-1}\right.$ soil sed $\left.^{-1}\right)$ & $0.85^{* *}$ & $0.57^{* *}$ & $0.96^{* *}$ & $0.71^{* *}$ \\
\hline OC micro within macro $\left(\mathrm{g} \mathrm{kg}^{-1}\right.$ soil sed $\left.^{-1}\right)$ & $0.72^{* *}$ & 0.22 & 0.58 & $0.58^{*}$ \\
\hline MWD & $0.78^{* *}$ & 0.13 & 0.30 & $0.81^{* *}$ \\
\hline Occluded oxidable OC $\left(\mathrm{g} \mathrm{kg}^{-1}\right.$ soil sed $\left.\mathrm{se}^{-1}\right)$ & $0.76^{* *}$ & 0.28 & 0.09 & $0.61^{* *}$ \\
\hline \multirow[t]{2}{*}{ Basal respiration $\left(\mathrm{mg} \mathrm{C}-\mathrm{CO}_{2} \mathrm{~kg}^{-1}\right.$ soil sed $^{-1}$ day $\left.^{-1}\right)$} & Eroding areas & Transport areas & \multicolumn{2}{|c|}{ Depositional areas } \\
\hline & & & Alluvial wedges & Reservoir \\
\hline Micro within macro (\%) & 0.27 & 0.11 & 0.07 & $0.61^{* *}$ \\
\hline OC macroaggregates $\left(\mathrm{g} \mathrm{kg}^{-1}\right.$ soil sed $\left.{ }^{-1}\right)$ & $0.57^{*}$ & 0.16 & $0.95^{* *}$ & $0.55^{* *}$ \\
\hline OC micro within macro $\left(\mathrm{g} \mathrm{kg}^{-1}\right.$ soil sed $\left.^{-1}\right)$ & 0.46 & 0.27 & 0.13 & $0.52^{*}$ \\
\hline $\mathrm{CN}$ & 0.43 & 0.12 & $0.65^{*}$ & -0.02 \\
\hline Occluded oxidable OC $\left(\mathrm{g} \mathrm{kg}^{-1}\right.$ soil sed $\left.^{-1}\right)$ & 0.51 & 0.10 & 0.16 & 0.41 \\
\hline OC- $M_{\text {pom }}$ & $0.73^{* *}$ & 0.10 & $0.68^{* *}$ & $0.75^{* *}$ \\
\hline OC stabilized in macroaggregates & -0.36 & 0.13 & $-0.61^{*}$ & -0.38 \\
\hline
\end{tabular}

Single asterisk, double asterisk, and bold font represent significance at $p<0.05, p<0.001$, and $p<0.10$, respectively.

displayed a lower aggregate stability and total OC content than the forest soils, but the same pattern of OC distribution within aggregates. Moreover, in the agricultural soils, the OC content in the free mineral fraction (OC-min) was higher than that in the occluded fractions (OC-Mm and OC-Mmin) (Fig. 4b). Altogether, this indicates the perturbation of these agricultural soils by land use change, tillage, and water erosion, which is also supported by the higher proportion of OC resistant to oxidation (Table 3) compared to forest soils; it also indicates the high capacity of Mediterranean calcareous soils for OC stabilization in organo-mineral complexes, in which the OC is less susceptible to mineralization (CourtierMurias et al., 2013; Trigalet et al., 2014; Garcia-Franco et al., 2015a). These stabilization mechanisms are common in Mediterranean areas and have been found at other sites close to the study area (Garcia-Franco et al., 2014, 2015b). From a geomorphological perspective, the agricultural soils showed a more rigorous selection of the detached OC produced by the perturbations cited above; as a consequence, the most stable, passive pool remained in these soils.

In the fluvial lateral banks, a lack of hierarchical order of aggregation was found, together with a lower OC content in all the aggregate size classes, compared to the forest and agricultural soils, despite the fact that the three sources had similar percentages of $\mathrm{M}$ and $\mathrm{Mm}$ aggregates. This indicates a decoupling of aggregates and OC, as found for other soils and land uses (Del Galdo et al., 2003; Denef et al., 2007), and contrasts with Elliott (1986), who reported that the distribution of $\mathrm{OC}$ associated with the aggregate fractions is primar- ily controlled by the amount of soil present in the fraction. However, in our study, such decoupling is explained by the fact that the fluvial lateral banks were sampled on average at $80 \mathrm{~cm}$ of depth, which is equivalent to a $\mathrm{C}$ horizon with a lack of soil formation and slow OC accumulation. This is consistent with the significantly lower BR rates observed in this source of sediments compared to those in the forest and agricultural soils, indicating very low microbial activity at this depth (Table 4). At the fluvial reach scale, the lateral banks were well connected to the channel, providing sediments to the main fluvial channels.

\subsection{Sediments and associated OC dynamics during transport}

During transport, a strong selection of texture and OC pools indicates that the most resistant $\mathrm{OC}$ was bound strongly to the mineral fraction (free and occluded), traveling the longest distances within the fluvial network. Compared to the bedload, the suspended sediments displayed a lower percentage of total macroaggregates (M) (30\% and $10 \%$ for the bedload and suspended sediments, respectively), but a greater amount of OC associated with this fraction (decoupling), mainly as intra-aggregate particulate organic matter $\left(M_{\text {pom }}\right)$ (Fig. 3a, b), suggesting mobilization of the most labile OC once the macroaggregates had been broken and resulting in less protection by physical and chemical processes. Other authors have reported how erosion enhances the release of easily mineralizable $\mathrm{C}$ encapsulated within aggregates in the min- 
eralization process (Six et al., 2004; Polyakov and Lal, 2008; Van Hemelryck et al., 2010; Wang et al., 2014; Nie et al., 2018) and how that labile OC is also more easily transported in suspension (Starr et al., 2000). On the other hand, the high labile OC $\left(\mathrm{OC}-M_{\text {pom }}\right)$ content in suspended sediments is consistent with the overall relatively higher BR rate and $\mathrm{C}: \mathrm{N}$ ratio, and lower aggregation and macroaggregate stabilization index, compared to the eroding and depositional areas (Tables 2 and 4), indicating that mineralization might be predominant during sediment transport.

Depletion of the total OC in suspended and bedload sediments of about $66 \%$ and $80 \%$, respectively, was observed when compared to the richest sediment source (forest soils). However, enrichments of OC in the suspended sediments and depletion in the bedload were observed compared to the agricultural soils and fluvial lateral banks. This, together with the positive correlation between total OC and clay $(r=0.48$; $p<0.05)$ and the higher clay content and lower aggregation observed in sediments during transport, demonstrates the selectivity of erosion during detachment and transport, as other authors have also reported (Starr et al., 2000).

Textural comparison of the sediment sources and sinks indicates that coarse material with low aggregation and a low OC content is selectively transported as bedload, while the finest and most labile material with a high OC content continues in transport as suspended load. Part of this OC might be (i) mineralized before deposition, (ii) mineralized once it has been deposited and before it is buried by following flooding events (Stallard et al., 1998), or (iii) transported longer distances. The similar presence of stable OC in macroaggregates (total occluded OC: OC-Mm + OC-Mmin), and OC resistant to oxidation (the most passive pool) in the transported sediments and the most erodible sources (agricultural soils and fluvial lateral banks; Table 3, Fig. 4b), indicates that the sediment came mainly from these eroding areas and that the more stable and resistant $\mathrm{OC}$ was not mineralized during transport. These results highlight the important role of both physical and chemical mechanisms in the protection of OC in transported sediments in semiarid and subhumid climates, where erosion can be a significant contributor to the regulation of catchment $\mathrm{C}$ budgets.

\subsection{Sediments and associated OC dynamics in depositional areas}

Compared to sediments coming from the poorest sources of OC within the catchment (i.e., agricultural soils and fluvial lateral banks) and to the transported sediments, a significant increase in the total OC, mainly associated with macroaggregates (OC-M; $>250 \mu \mathrm{m})$ and microaggregates within macroaggregates (OC-Mm), was observed at the surface layer of the depositional areas. This increase, much greater in the alluvial wedges than at the reservoir, supports the idea of new macroaggregate formation following the breakdown of aggregates during transport. Moreover, in the alluvial wedges, the OC concentration in these newly formed macroaggregates was higher than that in the microaggregates within macroaggregates in the agricultural soil and fluvial lateral bank sources, suggesting that aggregate formation and $\mathrm{OC}$ sequestration processes are occurring at the surface layer of these depositional areas. In fact, in these depositional areas, the distribution of OC within aggregates was similar to that observed in the forest soils, showing a decrease in the $\mathrm{OC}$ content with decreasing aggregate size and reinforcing the idea that $\mathrm{OC}$ accumulation occurs in the sediments of depositional sites. The formation of new aggregates, providing physical stabilization for eroded soil organic carbon in depositional positions, has been reported elsewhere (Berhe et al., 2012).

The similar (at the reservoir) or even higher (in the alluvial wedges) BR rates and enrichment of OC, compared to their main eroding sources (agricultural soils and fluvial lateral banks), indicate that new aggregates are being formed. Likewise, the positive correlations of the active pool $\left(M_{\text {pom }}\right)$ with the percentages of $\mathrm{M}$ and $\mathrm{Mm}$ at the reservoir, and with total OC-M and OC-Mm in both types of deposits, stress the role of the labile material in the activation of aggregate formation, as was also observed in the eroding areas. The formation of new aggregates might be favored by the growth of roots and the stimulation of microorganisms by root exudates of established terrestrial and aquatic vegetation at these depositional areas (Boix-Fayos et al., 2015). The formation of microaggregates within larger aggregates driven by microorganisms protects the $\mathrm{OC}$ associated with these microaggregates by increasing turnover time and leads to long-term $\mathrm{C}$ sequestration (García-Franco et al., 2015). Strong positive correlations between the OC- $M_{\text {pom }}$ and the occluded oxidable mineral fraction (rOC-Mmin - OC-Mmin) at the reservoir, similar to the correlations in the eroding areas (Table 5), suggest that, at this site, fresh OC inputs are more rapidly transformed by microorganisms in an oxidable pool, promoting aggregate formation and supporting the idea that the absorption of OC into the mineral surfaces (silt and clay) by chemical processes could enhance physical protection and thus longterm OC preservation (Kennedy et al., 2002; Kirkles et al., 2014; García Franco et al., 2015). Von Lützow et al. (2007) found that organic molecules stabilized by strong molecular interactions with mineral surfaces decomposed more slowly than OC stabilized by physical mechanisms (e.g., occlusion in soil aggregates). A lack of difference between the OC-Mm and OC-Mmin contents (Fig. 4b) indicates that both physical and chemical processes might be important with regard to the reservoir sediments acting as long-term residence deposits.

The higher percentages of $M_{\text {pom }}$ and Mm, but lower OC content associated with them at the reservoir, compared to the alluvial wedges at the surface layers (Fig. 4a, b), suggest differences in the temporal dynamics of aggregate formation between these two types of sediment deposit. The aggregate formation is slower in the alluvial wedges than at the reservoir, where the OC is also much more protected from de- 
composition by microorganisms than in the alluvial wedges (higher stabilized OC in macroaggregates; Table 4). In fact, at the reservoir, the OC occluded in aggregates $(\mathrm{Mm})$ represented about $20 \%$ more of the total OC, while BR rates were $66 \%$ lower (Table 4 ) than in the alluvial wedges. Altogether, these results indicate greater physicochemical protection of the OC in long-term residence deposits compared to medium-term ones.

In the deep layers of the depositional areas, the relatively lower OC, mineralization rates, and $M_{\text {pom }}$ were less favorable for aggregate formation and the process unfolded very slowly compared to the upper layers, which confirms the results reported by other authors (Xie et al., 2017). The reduction in BR rates with depth suggests that the OC has less chance of being released, which reinforces the $\mathrm{C}$ sink potential of these deposits at the deep layers in which a higher concentration of $\mathrm{OC}$ resistant to oxidation in the occluded fraction, relative to the free mineral fraction, indicates a higher OC stabilization compared to the upper layers (Table 3). In summary, the medium- and long-term depositional areas identified seem to be not only the main sinks for OC coming from different sources, but also areas of aggregate formation due to the microorganism activity stimulated by fresh OC inputs of established terrestrial and aquatic vegetation. Our results are in agreement with those of Doetterl et al. (2016), who indicated that depositional landform positions are not only able to store large OC stocks but also preserve OC more effectively when compared to eroding landscape positions.

\section{Conclusions}

Physicochemical mechanisms favoring OC stabilization in sources or eroding areas and the connectivity between the latter and channel areas determine both the redistribution of $\mathrm{OC}$ within catchments and the $\mathrm{C}$ dynamics. Good physicochemical protection of $\mathrm{OC}$ in the original sediment sources results in better protection of OC in sediments during fluvial transport and deposition downstream. In ephemeral or intermittent Mediterranean streams similar to our study site, sediments often originate from agricultural soils and fluvial lateral banks, in which the physicochemical protection of OC is much lower than that of forest soils less sensitive to erosion.

Different stabilization mechanisms were detected in the different sediment sources, transported sediments, and sedimentary deposits: (i) the predominance of physical mechanisms of OC stabilization in forest soils and alluvial wedges; and (ii) the predominance of chemical protection of OC in fluvial lateral banks. In the other positions, both processes are equally important in the stabilization of OC.

New processes of soil formation in the upper layers of the depositional areas and highly protected and stabilized OC stored in the deeper layers (mainly in the long-term deposits) strengthen the important role of depositional areas in ero- sive catchments, compensating for OC losses from eroded sources and functioning as $\mathrm{C}$ sinks.

These results underline the importance of studying soil erosion, soil formation, and geomorphological processes together in semiarid and subhumid catchments, where intermittent fluvial courses are predominant. Good management of these environments will be a powerful tool for climate change mitigation, given the high potential of alluvial settings as $\mathrm{C}$ sinks.

Data availability. Data used in this study are archived by the authors and are available on request.

Author contributions. CBF, MA, MMM, and JDV performed the field experimental design and field sampling. MA designed and performed the laboratory incubations, including the data processing and analysis; NGF and MMM developed the organic matter fractionation techniques, EG performed them at the laboratory, and MA performed data processing and analysis together with MMM; MMM wrote the paper with contributions from all authors.

Competing interests. The authors declare that they have no conflict of interest.

Acknowledgements. This work was financially supported by the project DISECO (CGL2014-55-405-R) from the Spanish Government, National Plan of Science. We thank the members of the Soil and Water Conservation Group (CEBAS-CSIC) who helped us in the field and laboratory work. María Almagro was supported by the Juan de la Cierva Program (grant IJCI-2015-23500). Carolina Boix-Fayos was also supported by a project from the program "Salvador de Madariaga" (PRXI7/00045) (Ministry of Education, Culture and Sport of Spain) and a project (20186/EE/17) of the Fundación Séneca (Regional Agency of Science of the Murcia Region) in the program "Jiménez de la Espada".

Review statement. This paper was edited by Ji-Hyung Park and reviewed by one anonymous referee.

\section{References}

Barreto, R. C., Madari, B. E., Maddock, J. E. L., Franchini, J., and Costa, A. R.: The impact of soil management on aggregation, carbon stabilization and carbon loss as $\mathrm{CO}_{2}$ in the surface layer of a Rhodic Ferralsol in Southern Brazil, Agr. Ecosyst. Environ., 132, 243-251. https://doi.org/10.1016/j.agee.2009.04.008, 2009.

Berhe, A. A. and Kleber, M.: Erosion, deposition, and the persistence of soil organic matter: Mechanistic considerations and problems with terminology, Earth Surf. Proc. Land., 38, 908912, https://doi.org/10.1002/esp.3408, 2013.

Berhe, A. A., Harden, J. W., Torn, M. S., Kleber, M., Burton, S. D., and Harte, J.: Persistence of soil organic matter in eroding versus 
depositional landform positions, J. Geophys. Res.-Biogeo., 117, G02019, https://doi.org/10.1029/2011JG001790, 2012.

Berhe, A. A., Barnes, R. T., Six, J., and Marín-Spiotta, E.: Role of Soil Erosion in Biogeochemical Cycling of Essential Elements: Carbon, Nitrogen, and Phosphorus, Annu. Rev. Earth Pl. Sc., 46, 521-548, https://doi.org/10.1146/annurev-earth-082517010018, 2018.

Boix-Fayos, C., Barbera, G. G., López-Bermúdez, F., and Castillo, V. M.: Effects of check dams, reforestation and land use changes on river channel morphology: Case study of the Rogativa catchment (Murcia, Spain), Geomorphology, 91, 103-123, https://doi.org/10.1002/hyp.7115, 2007.

Boix-Fayos, C., Nadeu, E., Quiñonero, J. M., Martínez-Mena, M., Almagro, M., and de Vente, J.: Sediment flow paths and associated organic carbon dynamics across a Mediterranean catchment, Hydrol. Earth Syst. Sci., 19, 1209-1223, https://doi.org/10.5194/hess-19-1209-2015, 2015.

Courtier-Murias, D., Simpson, A. J., Marzadori, C., Baldoni, G., Ciavatta, C., Fernández, J. M., López-de-Sá, E. G., and Plaza, C.: Unraveling the long-term stabilization mechanisms of organic materials in soils by physical fractionation and NMR spectroscopy, Agr. Ecosyst. Environ., 171, 9-18, https://doi.org/10.1016/j.agee, 2013.

Datry, T. Larned, S. T., and Tockner, K.: Intermittent Rivers: A Challenge for Freshwater Ecology, BioScience, 64, 229-235, https://doi.org/10.1093/biosci/bit027, 2014.

De Clercq, T., Heiling, M., Dercon, G., Resch, C., Aigner, M., Mayer, L. Mao, Y., Elsen, A., Steier, P., Leifeld, J., and Merck, R.: Predicting soil organic matter stability in agricultural fields through carbon and nitrogen stable isotopes, Soil Biol. Biochem., 88, 29-38, https://doi.org/10.1016/j.soilbio.2015.05.011, 2015.

De Girolamo, A. M., Bouraoui, F., Buffagni, A., Pappagallo, G., and Lo Porto, A.: Hydrology under climate change in a temporary river system: Potential impact on water balance and flow regime, River Res. Appl., 33, 1219-1232, https://doi.org/10.1002/rra.3165, 2017.

Del Galdo, I. Six, J., Peressotti, A., and Cotrufo, M. F.: Assessing the impact of land-use change on soil $\mathrm{C}$ sequestration in agricultural soils by means of organic matter fractionation and stable $\mathrm{C}$ isotopes, Glob. Change Biol., 9, 1204-1213, 2003.

Denef, K., Zotarelli, L., Boddey, R. M., and Six, J.: Microaggregate-associated carbon as a diagnostic fraction for management-induced changes in soil organic carbon in two Oxisols, Soil Biol. Biochem., 39, 1165-1172, https://doi.org/10.1016/j.soilbio.2006.12.024, 2007.

Denef, K. J., Six, J., Merckx, R., and Paustian, K.: Carbon sequestration in microaggregates of no-tillage soils with different clay mineralogy, Soil Sci. Soc. Am. J., 68, 1935-1944, ISSN: 03615995, 1435-0661, 2004.

Diehl, T. H.: A modified siphon sampler for shallow water: U.S. Geological Survey Scientific Investigations Report 2007-5282, 11 pp., 2008.

Doetterl, S., Six., J., Van Wesemael B., and Van Oost, K.: Carbon cycling in eroding landscapes: geomorphic controls on soil organic C pool composition and C stabilization, Glob. Change Biol., 18, 2218-2232, https://doi.org/10.1111/j.13652486.2012.02680.x, 2012.

Doetterl, S., Berhe, A., Nadeu, E., Wang, Z., Sommer, M., and Fiener, P.: Erosion, deposition and soil carbon: A review of process-level controls, experimental tools and models to address C cycling in dynamic landscapes, Earth-Sci. Rev., 154, 102-122 , https://doi.org/10.1016/j.earscirev.2015.12.005, 2016.

Elliott, E. T.: Aggregate structure and carbon, nitrogen, and phosphorus in native and cultivated soils, Soil Sci. Soc. Am. J., 50, 627-633, https://doi.org/10.2136/sssaj1986.03615995005000030017x, 1986.

Elliott, E. T., Palm, C. A., Reuss, D. E., and Monz, C. A: Organic matter contained in soil aggregates from a tropical chronosequence: correction for sand and light fraction, Agr. Ecosyst. Environ., 34, 443-451, https://doi.org/10.1016/01678809(91)90127-J, 1991.

Garcia-Franco, N., Wiesmeier, M., Goberna, M., MartínezMena, M., and Albaladejo, J.: Carbon dynamics after afforestation of semiarid shrublands: implications of site preparation techniques, Forest Ecol. Manage., 319, 107-115, https://doi.org/10.1016/j.foreco.2014.01.043, 2014.

Garcia-Franco, N., Martínez-Mena, M., Goberna, M., and Albaladejo, J.: Changes in soil aggregation and microbial community structure control carbon sequestration after afforestation of semiarid shrublands, Soil Biol. Biogeochem., 87, 110-121, https://doi.org/10.1016/j.soilbio.2015.04.012, 2015a.

Garcia-Franco, N., Albaladejo J., Almagro, M., and MartínezMena, M.: Beneficial effects of reduced tillage and green manure on soil aggregation and stabilization of organic carbon in a Mediterranean agroecosystem, Soil Till. Res., 153, 66-75, https://doi.org/10.1016/j.still.2015.05.010, 2015b.

Golchin, A., Clarke, P., Oades, J. M., and Skjemstad, J. O.: The effects of cultivation on the composition of organic-matter and structural stability of soils, Aust. J. Soil Res., 33, 975-993, https://doi.org/10.1071/SR9950975, 1995.

Gregorich, E. G., Greer, K. J., Anderson, D. W., and Liang, B. C.: Carbon distribution and losses: Erosion and deposition effects, Soil Till. Res., 47, 291-302, https://doi.org/10.1016/S01671987(98)00117-2, 1998.

Hoffmann, T., Mudd, S. M., van Oost, K., Verstraeten, G., Erkens, G., Lang, A., Middelkoop, H., Boyle, J., Kaplan, J. O., Willenbring, J., and Aalto, R.: Short Communication: Humans and the missing C-sink: erosion and burial of soil carbon through time, Earth Surf. Dynam., 1, 45-52, https://doi.org/10.5194/esurf-145-2013, 2013.

Howard, D. M. and Howard, P. J. A.: Relationships between $\mathrm{CO}_{2}$ evolution, moisture content and temperature for a range of soil types, Soil Biol. Biochem., 25, 1537-1537, https://doi.org/10.1016/0038-0717(93)90008-Y, 1993.

$\mathrm{Hu}, \mathrm{Y}$. and Kuhn, N. J.: Erosion-induced exposure of SOC to mineralization in aggregated sediment, Catena, 137, 517-525, https://doi.org/10.1007/s10533-016-0211-y, 2016.

IUSS Working Group WRB: World Reference Base for Soil Resources 2014, Update 2015. International Soil Classification System for Naming Soils and Creating Legends for Soil Maps, World Soil Resources Reports No. 106, Rome, FAO, 2015.

Kennedy, M. J., Pevear, D. R., and Hill, R. J.: Mineral surface control of organic carbon in black shale, Science, 295, 657-660, https://doi.org/10.1126/science.1066611, 2002.

Kirkels, F. M. S. A., Cammeraat L. H., and Kuhnb, N. J.: The fate of soil organic carbon upon erosion, transport and deposition in agricultural landscapes - A re- 
view of different concepts, Geomorphology, 226, 94-105, https://doi.org/10.1016/j.geomorph.2014.07.023, 2014.

Lal, R.: Soil erosion and carbon dynamics, Soil Till. Res., 81, 137142, https://doi.org/10.1016/j.still.2004.09.002, 2005.

Liu, C., Li, Z., Chang, X, He, J. Nie, X, Liu, L, Xiao, H. Wang, D., Peng, H., and Zeng, G.: Soil carbon and nitrogen sources and redistribution as affected by erosion and deposition processes: A case study in a loess hillygully catchment, China, Agr. Ecosyst. Environ., 253, 11-22, https://doi.org/10.1016/j.agee.2017.10.028, 2018.

Nadeu, E., de Vente, J. Martínez-Mena, M., and Boix-Fayos, C.: Exploring particle size distribution and organic carbon pools mobilized by different erosion processes at the catchment scale, J. Soil. Sediment., 11, 667-678, https://doi.org/10.1007/s11368011-0348-1, 2011.

Nadeu, E., Berhe, A. A., De Vente, J., and Boix-Fayos, C.: Erosion, deposition and replacement of soil organic carbon in Mediterranean catchments: a geomorphological, isotopic and land use change approach, Biogeosciences, 9, 1099-1111, https://doi.org/10.5194/bg-9-1099-2012, 2012.

Nie, X., Li, Z., Huang, J., Liu, L., Xiao, H., Liu, C., and Zeng, G.: Thermal stability of organic carbon in soil aggregates as affected by soil erosion and deposition, Soil Till. Res., 175, 82-90, https://doi.org/10.1016/j.still.2017.08.010, 2018.

Oades, J. M.: Soil organic matter and structural stability: mechanisms and implications for management, Plant Soil, 76, 319-337, 1984.

Oades, J. M. and Waters, A. G.: Aggregate hierarchy in soils, Aust. J. Soil Res., 29, 815-825, https://doi.org/10.1071/SR9910815, 1991.

Paul, E. A., Morris, S. J., and Boehm, S.: The determination of soil $\mathrm{C}$ pool sizes and turnover rates: biophysical fractionation and tracers, in: Assessment Methods for Soil Carbon (Advances in Soil Science),edited by: Lal, R., Kimble, J. M., Follett, R. F., and Stewart, B. A., CRC Press LLC, Boca Raton, FL, USA, 193-206, 2001

Pérez-Cutillas, P., Cataldo, M. F., Zema, D., de Vente, J., and BoixFayos, C.: Efectos de la revegetación a escala de cuenca sobre el caudal y la evapotranspiración en ambiente mediterráneo, Cuenca del Taibilla (SE de España), Bosque, 39, 119-129, 2018.

Polyakov, V. O. and Lal, R.: Soil organic matter and $\mathrm{CO}_{2}$ emission as affected by water erosion on field runoff plots, Geoderma, 143, 216-222, https://doi.org/10.1016/j.geoderma.2007.11.005, 2008.

Quinton, J., Govers, G., Van Oost, and Bardgett, R.: The impact of agricultural soil erosion on biogeochemical cycling, Nat. Geosci., 3, 311-314, https://doi.org/10.1038/ngeo838, 2010.

Quiñonero-Rubio, J. M., Nadeu, E., Boix-Fayos, C., and de Vente, J.: Evaluation of the Effectiveness of Forest Restoration and Check-Dams to Reduce Catchment Sediment Yield, Land Degrad. Dev., 27, 1018-1031, https://doi.org/10.1002/ldr.2331, 2016.

Ran, L., Lu, X. X., and Xin, Z.: Erosion-induced massive organic carbon burial and carbon emission in the Yellow River basin, China, Biogeosciences, 11, 945-959, https://doi.org/10.5194/bg11-945-2014, 2014.

Razafimbelo, T. M., Albrecht, A., Oliver, R., Chapuis-Lardy, L., and Feller, C.: Aggregate associated-C and physical protection in a tropical clayey soil under Malagasy conven- tional and no-tillage systems, Soil Till. Res., 98, 140-149, https://doi.org/10.1016/j.still.2007.10.012, 2008.

Salomé, C., Nunan, N., Pouteau, V., Lerch, T. Z., and Chenu, C.: Carbon dynamics in topsoil and in subsoil may be controlled by different regulatory mechanisms, Glob. Change Biol., 16, 416426, https://doi.org/10.1111/j.1365-2486.2009.01884.x, 2010.

Schewe, J., Heinke, J., Gerten, D., Haddeland, I., Arnell, N. W., Clark, D. B., Dankers, R., Eisner, S., Fekete, B. M., ColónGonzález, F. J., Gosling, S. N., Kim, H., Liu, X., Masaki, Y., Portmann, F. T., Satoh, Y., Stacke, T., Tang, Q., Wada, Y., Wisser, D., Albrecht, T., Frieler, K., Piontek, F., Warszawski, L., and Kabat, P.: Multimodel assessment of water scarcity under climate change, P. Natl. Acad. Sci. USA, 111, 3245-3250, https://doi.org/10.1073/pnas.1222460110, 2014.

Six, J. and Paustian, K.: Aggregate-associated soil organic matter as an ecosystem property and a measurement tool, Soil Biol. Biochem., 68, A4-A9, https://doi.org/10.1016/j.soilbio.2013.06.014, 2014.

Six, J., Elliott, E. T., and Paustian, K.: Soil structure and organic matter: I. Distribution of aggregate-size classes and aggregate-associated carbon, Soil Sci. Soc. Am. J., 64, 681-689, https://doi.org/10.2136/sssaj2000.642681x, 2000.

Six, J., Bossuyt, H., Degryze, S., and Denef, K. A.: history of research on the link between (micro)aggregates, soil biota, and soil organic matter dynamics, Soil Till. Res., 79, 7-31, https://doi.org/10.1016/j.still.2004.03.008, 2004.

Sodhi, G. P. S., Beri, V., and Benbi, D. K.: Soil aggregation and distribution of carbon and nitrogen in different fractions under longterm application of compost in rice-wheat system, Soil Till. Res., 103, 412-418, https://doi.org/10.1016/j.still.2008.12.005, 2009.

Stallard, R. F.: Terrestrial sedimentation and the carbon cycle: coupling weathering and erosion to carbon burial, Global Biogeochem. Cy., 12, 231-257, https://doi.org/10.1029/98GB00741, 1998.

Starr, G. C., lal, R., Malone, R., Hotherm, D., owens, L., and Kimble, J.: Modeling soil carbon transported by water erosion processes, Land Degrad. Dev., 11, 83-91, 2000.

Trigalet S., Van Oost, K. Roisin, C., and van Wesemael, B.: Carbon associated with clay and fine silt as an indicator for SOC decadal evolution under different residue management practices, Agr. Ecosyst. Environ., 196, 1-9, https://doi.org/10.1016/j.agee.2014.06.011, 2014.

Vadher, A. N., Millett, J., Stubbington, R., and Wood, P. J.: Drying duration and stream characteristics influence macroinvertebrate survivorship within the sediments of a temporary channel and exposed gravel bars of a connected perennial stream, Hydrobiologia, 814, 121-132, https://doi.org/10.1007/s10750-018-35449, 2018.

Van Hemelryck, H., Fiener, P., VanOost, K., and Govers, G.: The effect of soil redistribution on soil organic carbon: an experimental study, Biogeosciences, 7, 3971-3986, https://doi.org/10.5194/bg-7-3971-2010, 2010.

Van Hemelryck, H., Govers, G., Van Oost, K., and Merckx, R.: Evaluating the impact of soil redistribution on the in situ mineralization of soil organic carbon, Earth Surf. Proc. Land., 36, 427-438, https://doi.org/10.1002/esp.2055, 2011.

Van Oost, K., Quine, T. A., Govers, G., De Gryze, S., Six, J., Harden, W. J., Ritchie, J. C., McCarty, G. W., Heckrath, G., Kosmas, C., Giraldez, J. V., Marques da Silva, J. R., 
and Merckx, R.: The Impact of Agricultural Soil Erosion on the Global Carbon Cycle, Science New Series, 318, 626-629, https://doi.org/10.1126/science.1145724, 2007.

von Lützow, M., Kögel-Knabner, I., Ekschmitt, K., Flessa, H., Guggenberger, G.,Matzner, E., and Marschner, B.: SOM fractionation methods: relevance to functional pools and to stabilization mechanisms, Soil Biol. Biochem., 39, 2183-2207, https://doi.org/10.1016/j.soilbio.2007.03.007, 2007.

Wang, X., Liu, G., and Liu, S.: Effects of gravel on grassland soil carbon and nitrogen in the arid regions of the Tibetan Plateau, Geoderma, 166, 181-188, https://doi.org/10.1016/j.geoderma.2011.07.028, 2011.

Wang, X., Cammeraat, E., Cerli, C., and Kalbitz, K.: Soil aggregation and the stabilization of organic carbon as affected by erosion and deposition, Soil Biol. Biochem., 72, 55-65, https://doi.org/10.1016/j.soilbio.2014.01.018, 2014.
Wang, Z., Govers, G., Steegen, A., Clymans,W., Van den Putte, A., Langhans, C., Merckx, R., and Van Oost, K.: Catchmentscale carbon redistribution and delivery by water erosion in an intensively cultivated area, Geomorphology, 124, 65-74, https://doi.org/10.1016/j.geomorph.2010.08.010, 2010.

Wisser, D., Frolking, S., Hagen, S., and Bierken M. F. P: Beyond peak reservoir storage? A global estimate of declining water storage capacity in large reservoirs, Water Resour. Res., 49, 5732 5739, https://doi.org/10.1002/wrcr.20452, 2013.

Xie, J., Hou, M., Zhou, Y., Wang, R., Zhang, S., Yang, X., and Sun, B.: Carbon sequestration and mineralization of aggregateassociated carbon in an intensively cultivated Anthrosol in north China as affected by long term fertilization, Geoderma, 296, 1-9, https://doi.org/10.1016/j.geoderma.2017.02.023, 2017.

Zimmermann, M., Leifeld, J., Schmidt, N. W. I., Smith, P., and Fuhrer, J.: Measured soil organic matter fractions can be related to pools in the RothC model, Eur. J. Soil Sci., 58, 658-667, https://doi.org/10.1111/j.1365-2389.2006.00855.x, 2007. 